\title{
Expressão de galectina-3 e citoqueratina 19 nas neoplasias epiteliais da glândula tireóidea e correlação histopatológica
}

Primeira submissão em 29/04/04 Última submissão em 21/10/04 Aceito para publicação em 26/10/04 Publicado em 20/02/05

\author{
Expression of galectin-3 and cytokeratin 19 in the epithelial neoplasm of the thyroid gland and \\ histopathological correlation
}

Marilene Paladino Rosa'; Cristina T. Kanamura²; Marcos Brasilino de Carvalho ${ }^{3}$

\begin{abstract}
unitermos
Imuno-histoquímica

Neoplasia da glândula

tireóidea

Patologia

Galectina-3

Citoqueratina 19

\section{resumo}

Introdução: O câncer da glândula tireóidea é caracterizado pela sua variedade clínica e patológica. $O$ difícil diagnóstico pré-operatório das lesões foliculares induz a mais procedimentos cirúrgicos de caráter diagnóstico do que propriamente terapêutico. A proposta deste estudo foi identificar a expressão imuno-histoquímica das neoplasias epiteliais tireóideas utilizando anticorpos monoclonais para galectina-3 e citoqueratina 19 e correlacioná-la com variáveis histopatológicas. Material e método: A expressão da galectina-3 e da citoqueratina 19 foi estudada imuno-histoquimicamente em 84 casos com diagnóstico de tecido normal $(n=10)$, bócio adenomatoso $(n=8)$, adenoma folicular $(n=12)$, adenoma de célula de Hürthle $(n=3)$, carcinoma papilífero $(n=29)$, carcinoma folicular $(n=8)$, carcinoma insular $(n=$ 4), carcinoma de células de Hürthle $(n=4)$ e carcinoma indiferenciado $(n=6)$, selecionados a partir de pacientes operados no Serviço de Cirurgia de Cabeça e Pescoço do Hospital Heliópolis (HOSPHEL), no período de 1984 a 1995. Resultados: A expressão da galectina-3 foi observada em bócio adenomatoso $(12,5 \%)$, adenoma folicular $(16,7 \%)$, carcinoma papilífero $(96,6 \%)$, carcinoma folicular $(12,5 \%)$, carcinoma insular (50\%), carcinoma de célula de Hürthle (100\%) e carcinoma indiferenciado (50\%). Nossos resultados confirmaram a expressão significativa da galectina-3 no grupo das neoplasias malignas, principalmente no carcinoma papilífero. O padrão de expressão da citoqueratina 19 foi diferente entre os tipos de lesão: enquanto nos bócios e adenomas mostrou-se fraco, nos carcinomas papilíferos foi forte e difuso. Conclusão: Associadas, a galectina-3 e a citoqueratina 19 auxiliam o diagnóstico histopatológico, principalmente nas lesões de interpretação duvidosa, além de evidenciarem atipias e, com isso, determinarem uma lesão suspeita.
\end{abstract}

Background: The cancer of the thyroid gland is characterized by its clinical and pathological variety. The difficult preoperative diagnosis of the follicular lesions lead to more surgical procedures of diagnostic characteristic than therapeutic. The aim of this study was to identify the immunohistochemical expression of the thyroid epithelial neoplams using monoclonal antibodies for galectin-3 and cytokeratin 19, and correlate them with pathological variables. Material and methods: The expression of galectin-3 and cytokeratin 19, was immunohistochemically studied in 84 cases with diagnosis of normal tissue $(n=10)$, adenomatoid goiter $(n=8)$, follicular adenoma $(n=$ 12), Hürthle cell adenoma $(n=3)$, papillary carcinoma $(n=29)$, follicular carcinoma $(n=8)$, poorly differentiated carcinoma $(n=4)$, Hürthle cell carcinoma $(n=4)$, anaplastic carcinoma $(n=6)$, which were selected from patients treated at the Head and Neck Surgery Department of Hospital Heliópolis, from 1984 to 1995. Results: The expression of galectin-3 was observed in the cases of adenomatoid goiter (12.5\%), follicular adenoma (16.7\%), papillary carcinoma (96.6\%), follicular carcinoma (50\%), Hürthle cell carcinoma (100\%) and anaplastic carcinoma (50\%). Our results confirmed the significant expression of galectin-3 in the group of the malignant neoplasms, mainly in the papillary carcinoma. The expression pattern of cytokeratin 19 was different among the types of lesions; whereas in the goiters and adenomas it was weak, in the papillary carcinomas it was strong and diffuse. Conclusions: Galectin-3 and cytokeratin 19, associated, help the histopathological diagnosis, mainly in the lesions of difficult interpretation; besides they highlight atypical conditions and, thus, determine a suspicious lesion.

\footnotetext{
1. Mestra em Ciências da Saúde pelo Hospital Heliópolis (HOSPHEL); patologista do Laboratório de Anatomia Patológica do HOSPHEL.

2. Mestra em Farmácia; pesquisadora científica V do Instituto Adolfo Lutz.

3. Doutor em Cirurgia pela Faculdade de Ciências Médicas da Universidade Estadual de Campinas (FCM/UNICAMP); cirurgião do Serviço de Cirurgia de Cabeça e Pescoço do HOSPHEL. Trabalho apresentado como dissertação de mestrado em Ciências de Saúde, HOSPHEL, São Paulo, em 6 de junho de 2003, e realizado no Laboratório de Anatomia Patológica do HOSPHEL e na Divisão de Patologia do Laboratório de Imuno-Histoquímica do Instituto Adolfo Lutz.
}

key words

Immunohistochemistry

Thyroid neoplasms

Pathology

Galectin-3

Cytokeratin 19 


\section{Introdução}

As neoplasias da glândula tireóidea compreendem lesões benignas e malignas que se manifestam clinicamente através de nódulos no seu interior. Embora a doença nodular seja relativamente comum, o câncer é raro e representa menos de $1 \%$ de todas as neoplasias malignas. 0 diagnóstico diferencial clínico consiste em distinguir os nódulos malignos das outras afecções, neoplásicas ou não, capazes de deformar a glândula tireóidea e, assim, identificar os pacientes que necessitam de excisão cirúrgica.

A aplicação do método imuno-histoquímico na identificação das células foliculares normais e neoplásicas tem sido realizada na tentativa de fazer o diagnóstico diferencial entre as neoplasias tireóideas benignas e malignas, na avaliação pré-operatória, na correlação com atipias morfológicas e com prognóstico desfavorável(2, 7, 17).

Os padrões de expressão das citoqueratinas 7, 8, 18 e 19 nos distintos tipos de neoplasias tireóideas benignas e malignas despertaram interesse em novos estudos e apresentaram forte expressão em tecidos tireóideos normais e em carcinomas papilíferos, porém fraca expressão em carcinomas e adenomas foliculares. A citoqueratina 19 destacou-se por mostrar-se útil para a diferenciação entre o carcinoma papilífero e os adenomas e carcinomas foliculares ${ }^{(27)}$.

Apesar de alguns autores terem concluído que as citoqueratinas eram úteis na distinção entre as neoplasias epiteliais tireóideas, outros mostraram resultados diversos, limitando seu uso para diagnóstico(16).

Ao contrário das citoqueratinas, a galectina- 3 demonstrou, em estudos, a sua capacidade de discriminar neoplasias malignas e benignas na glândula tireóidea.

As galectinas são lectinas solúveis que se ligam a galactoses contendo glicoconjugados. Sua distribuição em tecidos sugere que têm função importante nos processos fisiológicos, como a diferenciação celular, e na transformação maligna. A galectina-3 foi associada à transformação maligna da célula tireóidea e sua expressão tem se mostrado positiva nos carcinomas papilíferos, foliculares e medulares e negativa em tecido tireóideo normal, adenomas e bócio ${ }^{(9,}$ 29). Porém existe divergência nos resultados quanto à positividade focal nas neoplasias benignas ${ }^{(5)}$.

Considerando que a expressão de citoqueratina 19 e galectina-3 nos tumores tireóideos apresenta-se predominantemente em estudos isolados na literatura, propusemonos a correlacioná-la com variáveis patológicas no intuito de esclarecer ou identificar critérios de malignidade.

\section{Objetivos}

Identificar a expressão da galectina-3 e da citoqueratina 19 nas neoplasias epiteliais tireóideas e correlacioná-la com variáveis histopatológicas.

\section{Material e método}

A partir de análise retrospectiva dos prontuários de pacientes portadores de doenças tireóideas atendidos no Serviço de Cirurgia de Cabeça e Pescoço do HOSPHEL, no período de 1984 a 1995, e que tinham sido submetidos a tireoidectomia, selecionamos blocos de espécimes cirúrgicos das neoplasias epiteliais que estavam arquivados na seção de anatomia patológica.

As amostras de tecido tireóideo tinham sido fixadas em formol a $10 \%$ e emblocadas rotineiramente em parafina. Foram selecionados 74 casos de neoplasias foliculares tireóideas, realizados novos cortes histológicos, corados por hematoxilina-eosina (HE), revisados histologicamente e classificados de acordo com Rosai(24), incluindo, assim, quatro casos de carcinomas de células de Hürthle, 29 de carcinomas papiliferos, oito de carcinomas foliculares, quatro de carcinomas insulares, seis de carcinomas indiferenciados, 12 de adenomas foliculares e três de adenomas de células de Hürthle, permanecendo um total de 66 casos de neoplasias epiteliais foliculares. Após a revisão histológica, oito casos anteriormente diagnosticados como adenoma folicular foram revistos e classificados como bócios adenomatosos. A estes foram acrescentados dez blocos de tecido tireóideo sem alterações neoplásicas provenientes de laringectomias totais. Este grupo, totalizando 18 casos, foi denominado tecido não-neoplásico e acrescentado ao estudo para efeito comparativo.

No estudo imuno-histoquímico foram utilizados os anticorpos primários específicos antigalectina 3 (clone 9C4, RDI, EUA), anticitoqueratina 19 (clone RCK 108, Dako, EUA), antitireoglobulina (policlonal em coelho, Dako, EUA) e o método da estreptavidina-biotina-peroxidase (kit LSAB, Dako, EUA) com recuperação antigênica através de calor úmido em panela de pressão com solução de ácido cítrico $10 \mathrm{mM} / \mathrm{pH} 6$.

O estudo das características histopatológicas foi feito através de microscopia ótica nas lâminas coradas em HE. Analisaram-se, nos grupos neoplásico e não-neoplásico, presença de mitoses atípicas e alteração nuclear em vidro fosco, sendo estas identificadas na contagem em dez campos óticos de maior aumento, através da objetiva de 40 . Nos carcinomas foi analisada a presença de invasão angiolinfática, invasão capsular e extensão extratireóidea. 
A presença de núcleo em vidro fosco foi analisada como positiva quando a disposição da cromatina se fazia na periferia do núcleo. Quanto à invasão angiolinfática, sua presença foi definida pela identificação de células neoplásicas isoladas ou em agrupamentos irregulares dentro dos vasos; e a extensão extratireóidea, quando o tumor ultrapassava a cápsula da glândula tireóidea.

Os carcinomas foram também agrupados em carcinomas diferenciados, que incluíam os foliculares e papilíferos; carcinomas pouco diferenciados, que incluíam os insulares e os indiferenciados.

Os carcinomas foliculares e os de células de Hürthle foram avaliados de acordo com o grau de invasão capsular, se minimamente invasivo ou se extensamente invasivo.

Os carcinomas papilíferos foram analisados de acordo com as variantes microscópicas: clássica, esclerosante, encapsulada, folicular e células altas.

A imunorreatividade positiva para galectina-3 e citoqueratina 19 foi identificada pela presença de precipitado castanho escuro no citoplasma das células do tecido tireóideo. Os casos positivos foram semiquantificados com base na relativa quantidade de células positivas em $1+$ a $3+$ :

- fraca (+): positividade em algumas células estimada em pelo menos $10 \%$ do total examinado;

- moderada (++): positividade de aproximadamente $11 \%$ a $50 \%$ das células;

- forte (+++) : positividade em grande número de células estimada em mais de $51 \%$.

A imunorreatividade para tireoglobulina, realizada para certificar-se da qualidade do material, foi considerada apenas presente ou ausente.

A associação entre as variáveis foi obtida através dos testes exatos de Fisher para freqüências, realizados com o auxílio do programa Graph Instat ${ }^{\circledR}$.

\section{Resultados}

A avaliação do grau de invasão capsular nos carcinomas foliculares revelou que cinco casos $(62,5 \%)$ eram minimamente invasivos e três $(37,5 \%)$, extensamente invasivos. Todos os quatro casos de carcinoma de células de Hürthle eram minimamente invasivos.

Os carcinomas papilíferos foram classificados de acordo com as variantes microscópicas e houve predomínio da variante clássica com 14 casos (48,3\%), seguida das variantes folicular, com sete casos (24,1\%); encapsulada, com cinco $(17,2 \%)$; esclerosante, com dois (6,9\%); e de células altas, com um caso (3,5\%). A invasão da cápsula tireóidea foi identificada em cinco dos 29 casos (17,2\%), e a invasão linfática, em seis (20,6\%).

A presença de mitoses atípicas predominou nas neoplasias e não esteve presente no grupo de tecido não-neoplásico (tecido glandular normal e bócio adenomatoso).

Houve um caso $(6,7 \%)$ de mitose atípica entre os adenomas (adenoma de célula de Hürthle) e oito (19,5\%) nos carcinomas, não mostrando diferença estatisticamente significativa quando estes dois grupos foram comparados. $\mathrm{O}$ mesmo acontecendo diante da comparação entre adenoma e tecido glandular sem neoplasia.

A análise da comparação de presença de mitoses atípicas entre o grupo dos carcinomas e o tecido glandular sem neoplasia mostrou diferença estatisticamente significante $(p=0,0143)$. O teste mostrou sensibilidade de $27 \%$, especificidade de $100 \%$, com valor preditivo positivo de $100 \%$ e valor preditivo negativo de 32\% (Tabela 1).

A presença de núcleo claro, também denominado núcleo em vidro fosco, nos adenomas foi de 12 casos (80\%), e nos carcinomas, de 31 (60,8\%), não sendo estatisticamente significativa quando comparamos os adenomas e os carcinomas.

Houve associação significativa quando os grupos de adenomas $(p=0,0004)$ e carcinomas $(p=0,0021)$ foram comparados, separadamente, com o grupo de tecido nãoneoplásico em relação à presença de núcleos claros (Tabela 2). $O$ teste para os carcinomas mostrou sensibilidade de $60 \%$, especificidade de $83 \%$, valor preditivo positivo de $91 \%$ e valor preditivo negativo de $42 \%$ (Tabela 2).

$\mathrm{O}$ estudo imuno-histoquímico realizado pesquisou os antígenos para tireoglobulina, galectina-3 e citoqueratina 19. A pesquisa de tireoglobulina realizada para assegurar a qualidade do material foi positiva em todos os casos de tecido tireóideo normal, bócio adenomatoso, adenoma folicular, adenoma de células de Hürthle, carcinoma folicular, carcinoma papilífero e carcinoma de células de Hürthle. Esteve negativa em dois casos de carcinoma insular e em quatro de carcinoma indiferenciado.

A pesquisa com galectina-3 foi positiva em dois bócios adenomatosos (22,2\%), dois adenomas foliculares $(16,6 \%)$, um caso de carcinoma folicular (12,5\%), em todos os casos de carcinoma de células de Hürthle, em 28 carcinomas papilíferos $(96,5 \%)$, em três carcinomas indiferenciados (50\%) e em dois carcinomas insulares (50\%). Esteve negativa nos casos de adenoma de células de Hürthle e em todos os dez casos controle (Tabela 3). A expressão positiva mostrou-se predominantemente no citoplasma (Figura 1). 
Tabela 1 de mitoses atipicas

\begin{tabular}{lccc} 
& \multicolumn{2}{c}{ Mitoses atípicas } & Total \\
Diagnóstico histopatológico & Presentes (\%) & Ausentes (\%) & 10 \\
Tecido normal & $0(-)$ & $10(100)$ & 8 \\
Bócio adenomatoso & $0(-)$ & $8(100)$ & 12 \\
Adenoma folicular & $0(-)$ & $12(100)$ & 3 \\
Adenoma de células de Hürthle & $1(33,3)$ & $2(66,7)$ & 29 \\
Carcinoma papilífero & $6(20,7)$ & $23(79,3)$ & 4 \\
Carcinoma de células de Hürthle & $0(-)$ & $4(100)$ & 8 \\
Carcinoma folicular & $2(25)$ & $6(75)$ & 4 \\
Carcinoma insular & $3(75)$ & $1(25)$ & 6 \\
Carcinoma indiferenciado & $3(50)$ & $3(50)$ & 84 \\
Total & $15(17,9)$ & $69(82,1)$ & \\
\hline
\end{tabular}

\section{Tabela 2 Distribuição dos pacientes segundo o diagnóstico histopatológico e a presença de núcleo claro}

\begin{tabular}{lc} 
Diagnóstico histopatológico & Presente (\%) \\
Tecido normal & $2(20)$ \\
Bócio adenomatoso & $1(12,5)$ \\
Adenoma folicular & $9(75)$ \\
Adenoma de células de Hürthle & $3(100)$ \\
Carcinoma papilífero & $24(82,8)$ \\
Carcinoma folicular & $4(50)$ \\
Carcinoma insular & $1(25)$ \\
Carcinoma de células de Hürthle & $2(50)$ \\
Carcinoma indiferenciado & $0(-)$ \\
Total & $\mathbf{4 6 ( 5 4 , 7 )}$ \\
\hline
\end{tabular}

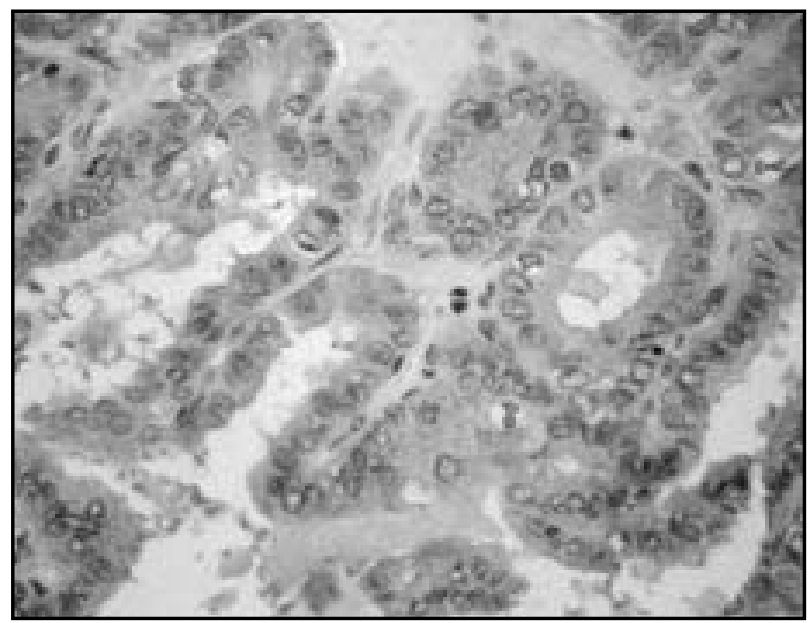

Figura 1 - Fotomicrografia de corte histológico de carcinoma papilífero mostrando reatividade para galectina-3 (400x)

\section{Núcleo claro}

$\begin{array}{cc}\text { Ausente }(\%) & \text { Total } \\ 8(80) & 10 \\ 7(87,5) & 8 \\ 3(25) & 12 \\ 0(-) & 3 \\ 5(17,2) & 29 \\ 4(50) & 8 \\ 3(75) & 8 \\ 2(50) & 4 \\ 6(100) & 6 \\ 38(45,3) & 84\end{array}$

Houve diferença estatisticamente significativa $(p<0,0001)$ quando comparamos carcinomas e adenomas segundo a expressão de galectina-3, assim como as comparações entre adenomas e carcinomas diferenciados (carcinoma papilífero, folicular e de células de Hürthle), entre adenomas foliculares e carcinomas papilíferos, entre adenomas e carcinomas de células de Hürthle e entre carcinomas e o grupo de tecido não-neoplásico também se mostraram estatisticamente significativas.

A comparação entre adenomas e carcinomas foliculares não foi estatisticamente significativa.

Ao analisarmos a reatividade da galectina- 3 no grupo dos carcinomas em relação ao tecido não-neoplásico, a sensibilidade foi de $74,5 \%$, e a especificidade, de $94,5 \%$, 
com valores preditivos positivo e negativo de $97 \%$ e $56 \%$, respectivamente.

A pesquisa de citoqueratina 19 foi positiva em três casos de bócio adenomatoso (37,5\%), em cinco adenomas foliculares $(41,7 \%)$, em dois adenomas de células de Hürthle (50\%), em 25 carcinomas papilíferos (86,5\%), em dois carcinomas foliculares (25\%), em dois carcinomas de células de Hürthle (50\%) e em um carcinoma indiferenciado $(16,7 \%)$. Esteve negativo em todos os carcinomas insulares (Figura 2). $\mathrm{O}$ tecido normal mostrou-se reativo em nove casos de forma focal e dispersa (Tabela 4).
Houve associação significativa $(p=0,0066)$ quando comparamos o grupo dos adenomas foliculares com o dos carcinomas papilíferos.

A análise estatística mostrou que a positividade da citoqueratina 19 entre os grupos dos adenomas e carcinomas, dos carcinomas e tecido não-neoplásico, dos adenomas com os carcinomas diferenciados e dos adenomas foliculares com carcinomas foliculares não foi estatisticamente significativa.

O grau de invasão capsular nos carcinomas foliculares e a reatividade da galectina-3 e da citoqueratina 19 não mostraram associação entre si. Todos os carcinomas de

Tabela 3 Reatividade imuno-histoquímica da galectina-3 segundo o diagnóstico histopatológico

$\begin{array}{lc}\text { Diagnóstico histopatológico } & \text { Positiva } n(\%) \\ \text { Tecido normal } & 0(-) \\ \text { Bócio adenomatoso } & 1(12,5) \\ \text { Adenoma folicular } & 2(16,7) \\ \text { Adenoma de células de Hürthle } & 0(-) \\ \text { Carcinoma papilífero } & 28(96,6) \\ \text { Carcinoma folicular } & 1(12,5) \\ \text { Carcinoma insular } & 2(50) \\ \text { Carcinoma de células de Hürthle } & 4(100) \\ \text { Carcinoma indiferenciado } & 3(50) \\ \text { Total } & 41(48,8)\end{array}$

\section{Galectina-3}

Negativa $n(\%)$

$10(100) \quad 10$

$7(87,5)$

$10(83,3) \quad 12$

$3(100) \quad 3$

$1(3,4) \quad 29$

$7(87,5) \quad 8$

$2(50) \quad 8$

$0(-)$

$3(50) \quad 6$

$43(51,2) \quad 84$

Tabela 4 Reatividade imuno-histoquímica da citoqueratina 19 segundo o diagnóstico histopatológico

Diagnóstico histopatológico

Tecido normal

Bócio adenomatoso

Adenoma folicular

Adenoma de células de Hürthle

Carcinoma papilífero

Carcinoma folicular

Carcinoma insular

Carcinoma de células de Hürthle

Carcinoma indiferenciado

Total

\section{Citoqueratina 19}

Positiva $n(\%)$
$9(90)$
$3(37,5)$
$5(41,7)$
$2(66,7)$
$25(86,2)$
$2(25)$
$0(-)$
$2(50)$
$1(16,7)$
40

Negativa $n(\%)$

$1(10)$

Total

$5(62,5) \quad 8$

$7(58,3) \quad 12$

$1(33,3)$

$4(17,8) \quad 29$

$6(75) \quad 8$

$4(100) \quad 8$

$2(50) \quad 4$

$5(83,3) \quad 6$

$44 \quad 84$ 


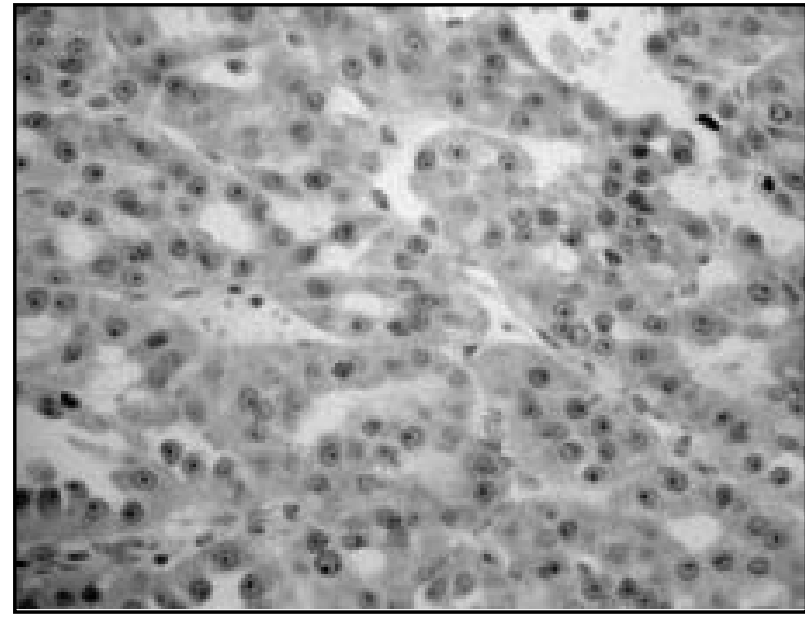

Figura 2 - Fotomicrografia de corte histológico de carcinoma de células de Hürthle mostrando reatividade para citoqueratina 19 (400x)

células de Hürthle apresentavam invasão mínima da cápsula, sendo que a positividade para galectina- 3 foi de $4 / 4$ e da citoqueratina 19, de dois em quatro casos.

Nos casos de carcinoma papilífero foram detectadas invasão linfática em seis $(20,7 \%)$ e invasão capsular em cinco $(17,3 \%)$ dos 29 casos. Estas duas variáveis, quando comparadas individualmente com a reatividade da galectina-3 e da citoqueratina 19, não apresentaram associação significativa.

A presença de mitoses atípicas e núcleo claro no grupo dos carcinomas diferenciados não foi significativa quando comparada à positividade para galectina-3 e citoqueratina 19.

\section{Discussão}

\section{Aspectos histopatológicos}

O grau de invasão capsular é um elemento importante para a avaliação do prognóstico nos carcinomas foliculares, além de ser fator fundamental para a afirmação do diagnóstico, o que requer uma representação adequada da cápsula para estudo histológico, definindo-se assim o carcinoma folicular de invasão mínima e o carcinoma folicular extensamente invasivo. Neste estudo, entre os oito carcinomas foliculares, encontramos cinco casos $(62,5 \%)$ minimamente invasivos e três $(37,5 \%)$ extensamente invasivos, o que se assemelha ao estudo de outros autores ${ }^{(15)}$, em que cerca de $66 \%$ dos casos eram minimamente invasivos.

O carcinoma papilífero é o tumor maligno mais comum da glândula tireóidea e apresenta uma variedade de tipos morfológicos. O tipo clássico é o mais freqüente, seguido da variante folicular que possui comportamento clínico e biológico semelhante, demonstrado em estudo com 59 carcinomas. Os casos de carcinoma papilífero tiveram incidência de $42,4 \%$ da variante clássica, $13,6 \%$ da folicular e $3,4 \%$ da variante de células altas ${ }^{(15)}$. Nossos dados concordaram com a literatura e apresentaram $48,3 \%$ de carcinoma papilífero clássico, $24,1 \%$ de variante folicular, $17,2 \%$ de variante encapsulada, $6,9 \%$ de microcarcinoma esclerosante e $3,5 \%$ de células altas.

A invasão capsular tireóidea nos carcinomas papilíferos foi de $17,2 \%$ (cinco casos), e a invasão linfática, de 20,6\% (seis casos), semelhante ao relatado por Donohue et al.

O estudo morfológico da presença de mitoses atípicas e núcleo claro mostrou-se significativo nos casos de carcinoma em relação ao tecido não-neoplásico, porém, quanto à diferenciação entre as lesões benignas e malignas, que seria de maior utilidade na prática diagnóstica, não se mostrou adequado. Resultados semelhantes têm sido relatados na literatura, e a opinião mais aceita é de se considerar que somente as atipias citológicas isoladamente não poderiam servir de fator diagnóstico para malignidade ${ }^{(18,21)}$.

\section{Estudo imuno-histoquímico}

\section{Galectina-3}

Os resultados do presente estudo confirmaram a significativa expressão da galectina-3 no grupo das neoplasias malignas em concordância com os dados da literatura, principalmente no grupo dos carcinomas papilíferos, onde a positividade esteve presente em $96,6 \%$ dos $\operatorname{casos}^{(28,29)}$.

As comparações entre os adenomas e os grupos de carcinomas também mostraram-se com diferenças estatisticamente significativas, o que denota um poder discriminatório da galectina-3 para neoplasia maligna diferenciada muito eficiente, principalmente ao exibirem alta especificidade e elevado valor preditivo positivo.

No Quadro 1 resumimos a expressão da galectina-3 nas neoplasias e nas lesões não-neoplásicas da glândula tireóidea de acordo com a literatura, incluindo o presente estudo.

Neste trabalho tivemos a expressiva positividade nos carcinomas papilíferos. Dos 12 casos de adenomas foliculares, dez não mostraram qualquer reação positiva, enquanto dois tiveram positividade focal em células atípicas com núcleos claros e volumosos. Nos casos de bócio adenomatoso, tivemos um com positividade difusa presente em microfolículos sem células atípicas. 
Quadro 1 Expressão da galectina-3 em lesões tireóideas benignas e malignas segundo estudos realizados

\begin{tabular}{|c|c|c|c|c|c|c|c|c|c|}
\hline & & & Imunorr & reatividade & das lesões $t$ & tireóideas & & & \\
\hline Autores & $\begin{array}{l}\text { Carcinoma } \\
\text { papilifero }\end{array}$ & $\begin{array}{l}\text { Carcinoma } \\
\text { folicular }\end{array}$ & $\begin{array}{l}\text { Carcinoma } \\
\text { céls. Hürthle }\end{array}$ & $\begin{array}{l}\text { Carcinoma } \\
\text { pouco dif. }\end{array}$ & $\begin{array}{l}\text { Carcinoma } \\
\text { anaplásico }\end{array}$ & $\begin{array}{l}\text { Adenoma } \\
\text { folicular }\end{array}$ & $\begin{array}{l}\text { Adenoma } \\
\text { céls. Hürthle }\end{array}$ & $\begin{array}{c}\text { Bócio } \\
\text { adenomatoso }\end{array}$ & $\begin{array}{l}\text { Anticorpo } \\
\text { utilizado }\end{array}$ \\
\hline Xu et al. & $16 / 16$ & $7 / 7$ & - & - & - & $0 / 10$ & - & $0 / 1$ & $\begin{array}{c}\text { Rat Moab } \\
\text { M3/38 }\end{array}$ \\
\hline $\begin{array}{l}\text { Fernandez } \\
\text { et al. }\end{array}$ & $18 / 18$ & $4 / 8$ & $1 / 1$ & $2 / 3$ & $5 / 5$ & $0 / 8$ & - & $0 / 8$ & $\begin{array}{l}\text { Policlonal } \\
\text { de coelho }\end{array}$ \\
\hline $\begin{array}{l}\text { Cvejic } \\
\text { et al. }\end{array}$ & $20 / 20$ & $11 / 15$ & $2 / 2$ & - & $10 / 10$ & $5 / 14$ & - & - & $\begin{array}{c}\text { Rat Moab } \\
\text { M3/38 }\end{array}$ \\
\hline $\begin{array}{l}\text { Orlandi } \\
\text { et al. }\end{array}$ & $18 / 18$ & $6 / 6$ & $8 / 8$ & $3 / 3$ & - & $3 / 29$ & - & - & $\begin{array}{c}\text { Rat Moab } \\
\text { M3/38 }\end{array}$ \\
\hline $\begin{array}{c}\text { Inohara } \\
\text { et al. }\end{array}$ & $45 / 45$ & $8 / 8$ & - & - & $5 / 5$ & $0 / 25$ & - & $0 / 3$ & $\begin{array}{c}\text { Rat Moab } \\
\text { M3/38 }\end{array}$ \\
\hline $\begin{array}{c}\text { Gasbarri } \\
\text { et al. }\end{array}$ & $28 / 30$ & $14 / 14$ & - & - & $3 / 4$ & $1 / 37$ & - & $0 / 32$ & $\begin{array}{c}\text { Rat Moab } \\
\text { M3/38 }\end{array}$ \\
\hline $\begin{array}{l}\text { Nascimento } \\
\text { et al. }\end{array}$ & $9 / 11$ & $11 / 14$ & $10 / 17$ & - & - & $1 / 9$ & $1 / 14$ & & $\begin{array}{c}\text { MoAb } \\
\text { gal-3 } 9 \mathrm{C} 4\end{array}$ \\
\hline $\begin{array}{l}\text { Bartolazzi } \\
\text { et al. }\end{array}$ & $195 / 201$ & $54 / 57$ & $13 / 13$ & $13 / 20$ & $18 / 20$ & $4 / 125$ & $1 / 7$ & $0 / 50$ & $\begin{array}{c}\text { MoAb } \\
\text { gal-3 9C4 }\end{array}$ \\
\hline $\begin{array}{l}\text { Saggiorato } \\
\text { et al. }\end{array}$ & - & $16 / 17$ & - & - & - & $4 / 52$ & - & - & $\begin{array}{c}\text { MoAb } \\
\text { gal-3 9C4 }\end{array}$ \\
\hline Coli et al. & $28 / 28$ & $3 / 5$ & $1 / 1$ & $2 / 3$ & $1 / 1$ & $17 / 27$ & - & $7 / 25$ & $\begin{array}{c}\text { MoAb } \\
\text { gal-3 } 9 \mathrm{C} 4\end{array}$ \\
\hline $\begin{array}{c}\text { Hermann } \\
\text { et al. }\end{array}$ & $12 / 45$ & $2 / 3$ & $5 / 8$ & $1 / 3$ & $1 / 2$ & $1 / 3$ & - & $0 / 1$ & $\begin{array}{c}\text { MoAb } \\
\text { gal-3 } 9 \mathrm{C} 4\end{array}$ \\
\hline $\begin{array}{l}\text { Beesley e } \\
\text { McLaren }\end{array}$ & $22 / 26$ & $12 / 12$ & - & - & $0 / 1$ & $2 / 20$ & - & $3 / 8$ & $\begin{array}{c}\text { MoAb } \\
\text { gal-3 } 9 \mathrm{C4}\end{array}$ \\
\hline $\begin{array}{r}\text { Presente } \\
\text { estudo }\end{array}$ & $28 / 29$ & $1 / 8$ & $4 / 4$ & $2 / 4$ & $3 / 6$ & $2 / 12$ & $0 / 3$ & $1 / 8$ & $\begin{array}{c}\text { MoAb } \\
\text { gal-3 } 9 \mathrm{C} 4\end{array}$ \\
\hline
\end{tabular}

$\mathrm{Na}$ literatura, relatos de imunorreatividade em adenomas foliculares estão presentes, sendo que alguns destes autores relataram hipóteses de que a expressão da galectina3 demonstraria características de malignidade, indicando a conversão para carcinoma, o que necessitaria de novos estudos para confirmação $(5,6,12,13,21,22,25)$.

A expressão de galectina-3 obtida em nosso estudo nos carcinomas foliculares foi classificada como extensamente invasiva em um dos oito casos. Este resultado não acompanha a literatura, que apresenta de $50 \%$ a $100 \%$ de positividade nos casos de carcinoma folicular ${ }^{(3,12,14}$, 22, 29). Apesar de a progressão do adenoma folicular para o carcinoma folicular ou do carcinoma folicular para o carcinoma papilífero não ser aceita como verdadeira, o aumento da galectina-3 pode estar relacionado com a formação de estruturas papilíferas, sendo uma questão que pode ser esclarecida com estudos futuros, e, caso isto fosse confirmado, explicaria a não-reatividade nos nossos casos de carcinoma folicular de invasão mínima. 
A falta de expressão positiva da galectina-3 nos carcinomas foliculares tornou a comparação com o grupo dos adenomas foliculares não-significante. Ao contrário, a comparação entre as neoplasias de células de Hürthle benignas e malignas se mostrou significante, apesar da casuística ser pequena e concordando com os dados da literatura que consideram a galectina-3 um marcador tumoral para estas neoplasias ${ }^{(21)}$.

Considerando-se que a expressão da galectina-3 possui poder discriminatório entre adenomas e carcinomas, entre as neoplasias benignas e malignas de células de Hürthle e uma significativa expressão nos carcinomas papilíferos, acreditamos que o emprego da galectina-3 deva ser útil na avaliação das lesões com histologia duvidosa em que há suspeita de malignização, além da utilização em métodos diagnósticos pré-cirúrgicos, como na punção aspirativa por agulha fina, fazendo, assim, uma melhor avaliação das lesões de padrão folicular ${ }^{(14)}$.

A marcação de células atípicas, através da expressão da galectina-3, nas lesões benignas deve ser considerada para novos estudos.

\section{Citoqueratina 19}

A utilização do estudo da citoqueratina 19 na glândula tireóidea relaciona-se aos problemas nos diagnósticos diferenciais ${ }^{(10,19)}$, quando da manifestação histológica de formações papilíferas nas lesões benignas, sem as alterações citológicas características de núcleo claro, inclusão e fendas que firmariam o diagnóstico de carcinoma papilífero. Estas formações podem ser encontradas em bócios multinodulares, adenomas foliculares e tecidos tireóideos com hiperplasia.

A comparação entre os adenomas foliculares e os carcinomas papilíferos mostrou-se com diferenças estatisticamente significativas, o que confere à expressão da citoqueratina 19 um poder discriminatório entre o carcinoma papilífero variante folicular e os adenomas foliculares e as hiperplasias papilíferas benignas.

Neste estudo encontramos positividade difusa e intensa nos carcinomas papilíferos, que estavam presentes em $86,2 \%$, enquanto nos carcinomas foliculares houve expressão em $25 \%$. A expressão nos bócios adenomatosos e adenomas foliculares foi focal, de fraca a moderada, e esteve presente em $37,5 \%$ e $41,7 \%$, respectivamente. Assim como em nosso estudo, outros autores ${ }^{(4,8,11,20)}$ relataram a presença de citoqueratina 19 no tecido tireóideo normal de forma fraca e dispersa, e de maneira oposta nos carcinomas papilíferos, de forma forte e difusa, presente em todos os casos.
Nos casos de bócios adenomatosos, a positividade da citoqueratina 19 em nosso estudo foi de $37,5 \%$, menor que a observada por eles, que foi de $100 \%$, apesar de apresentar uma distribuição fraca e dispersa em $70 \%$ dos casos. A comparação com os resultados dos adenomas foliculares e adenomas de células de Hürthle foi da mesma forma, e nos carcinomas foliculares a positividade em nosso estudo foi de $25 \%{ }^{(2-8)}$ contra $86,3 \%$, sendo sua distribuição de forma intensa em $73 \%$ dos casos. Não foi possível, neste estudo, estabelecer diferenças entre adenomas e carcinomas foliculares, como realizado por outros autores ${ }^{(20)}$, que por obterem positividade maior nos carcinomas foliculares, sugerem que a transformação maligna aumenta a expressão da citoqueratina. Acreditamos que novos estudos devam ser realizados para esclarecimento e confirmação destas observações.

Estas variações talvez possam ser explicadas pelo maior número de casos avaliados, porém a distribuição da positividade em nosso estudo foi diferente entre os tipos de lesão. Enquanto nos bócios mostrou-se fraca, nos carcinomas papilíferos foi forte e difusa. Concordamos que estas variações possam ser úteis na separação entre hiperplasia papilífera benigna e o carcinoma papilífero, assim como na diferenciação dos adenomas foliculares e carcinomas papilíferos variante folicular ${ }^{(23,26,27)}$.

Neste estudo, tivemos quatro casos de carcinoma papilifero com reação negativa à citoqueratina 19 , sendo que dois casos eram variantes foliculares, um de célula alta e um clássico.

As razões para as divergências em relação às variações entre a intensidade das reações nos adenomas foliculares relatadas por diversos autores ainda não estão claras, mas podem ser decorrentes dos clones dos anticorpos utilizados e das variações das técnicas realizadas em cada instituição. Novos estudos serão necessários para mostrar se há diferenças no comportamento clínico e para estabelecer um padrão de reatividade destas neoplasias ${ }^{(1,4)}$.

A forte e difusa positividade da citoqueratina 19 isoladamente não pode ser considerada diagnóstica de carcinoma papilífero, porém, em lesões tireóideas com padrão folicular, devem ser consideradas suspeitas para o carcinoma papilífero variante folicular, sendo necessário um estudo minucioso para o encontro de alterações nucleares dos carcinomas papilíferos. Porém, a expressão da citoqueratina 19 nas lesões benignas, mesmo que seja de forma fraca e focal, requer interpretação criteriosa para que possa ser usada auxiliando o diagnóstico histopatológico.

Estudos com os dois marcadores, citoqueratina 19 e galectina-3, sugerem a utilização em conjunto para o 
diagnóstico histopatológico nas lesões tireóideas solitárias, pois a citoqueratina 19 favorece o diagnóstico de carcinoma papilífero e suas variantes, e a galectina-3, além do carcinoma papilífero, pode reconhecer os carcinomas foliculares ${ }^{(3)}$. Concordamos com estes autores, pois, apesar de os resultados nos carcinomas foliculares não terem sido discriminatórios em relação ao adenoma folicular, no estudo agrupado dos carcinomas tivemos resultados significativos. Assim, o uso dos dois marcadores auxiliaria a análise das lesões foliculares com alterações citológicas que não atingem os critérios de malignidade.

A rotina diagnóstica na patologia de tumores da glândula tireóidea pode ser auxiliada com a indicação criteriosa da galectina-3 e da citoqueratina 19, que, associadas ao exame morfológico, definiriam melhor as denominadas neoplasias foliculares de comportamento maligno indeterminado. $\mathrm{O}$ uso destes marcadores como método diagnóstico pré-cirúrgico em material citológico proveniente de punção aspirativa por agulha fina indicaria, com melhor precisão, as lesões tireóideas que necessitam de tratamento cirúrgico.

\section{Conclusões}

A galectina-3 é um marcador de malignidade por estar presente significativamente nos carcinomas diferenciados, e sua expressão em lesões benignas pode evidenciar atipias citológicas e, com isso, determinar uma lesão suspeita. A citoqueratina 19, quando expressada forte e difusamente, pode ser usada para estabelecer o diagnóstico de carcinoma papilífero.

A galectina-3 e a citoqueratina 19, associadas, devem compor um painel imuno-histoquímico para auxiliar o diagnóstico nas lesões tireóideas de interpretação morfológica duvidosa.

\section{Referências}

I. BALOCH, Z.W. et al. Differential expression of cytokeratins in follicular variant of papillary carcinoma: an immunohistochemical study and its diagnostic utility. Human Pathol, v. 30, p. I 166-7I, 1999.

2. BARTOLAZZI,A. et al.Thyroid Cancer Study Group. Application of an immunodiagnostic method for improving preoperative diagnosis of nodular thyroid lesions. Lancet, v. 26, p. $1644-$ 50, 2001.

3. BEESLEY, M. F.; MCLAREN, K. M. Cytokeratin 19 and galectin-3 immunohistochemistry in the differential diagnosis of solitary thyroid nodules. Histopathology, v. 4 I, p. 236-43, 2002.

4. CHEUNG, C. C.et al. Immunohistochemical diagnosis of papillary thyroid carcinoma. Mod Pathol, v. I4, n. 4, p. 338-42, 2001.

5. COLI, A. et al. Galectin-3 a marker of well-differentiated thyroid carcinoma, is expressed in thyroid nodules with cytological atypia. Histopathology, v. 40, p. 80-7, 2002.

6. CVEJIC, D. et al. Immunohistochemical localization of galectin-3 in malignant and benign human thyroid tissue. Anticancer Res, v. 18, n. 4A, p. 2637-4I, 1998.

7. DONOHUE, J. H. et al. Do the prognoses of papillary and follicular thyroid carcinomas differ? Am J Surg, v. 148, p. 168-73, 1984

8. ERKILIC, S. et al. Diagnostic utility of cytokeratin 19 expression in multinodular goiter with papillary areas and papillary carcinoma of thyroid. Endocr Pathol, v. I3, n. 3, p. 207- I I, 2002.

9. FERNANDEZ, P. L. et al. Galectin-3 and laminin expression in neoplastic and non neoplastic thyroid tissue.J Pathol, v. I81, p. 80-6, 1997.

I0. FONSECA, E.; SOBRINHO-SIMÕES, M. Diagnostic problems in differentiated carcinomas of the thyroid. Path Res Pract, v. 191, p. 318-31, 1995.
I I.FONSECA, E. et al.Pattern of expression of intermediate cytokeratin filaments in the thyroid gland: an immunohistochemical study of simple and stratified epithelial-type cytokeratins. Virchows Arch, v. 430, p. 239-45, 1997.

12. GASBARRI, A. et al. Galectin-3 and CD44v6 isoforms in the preoperative evaluation of thyroid nodules. J Clin Oncol, v. I7, n. I I, p. 3494-502, 1999.

13. HERMANN, M. E. et al. Immunohistochemical expression of galectin-3 in benign and malignant thyroid lesions. Arch Pathol Lab Med, v. 126, p. 7I0-3, 2002

I4. INOHARA, H. et al. Expression of galectin-3 in fine-needle aspirates as a diagnostic marker differentiating benign from malignant thyroid neoplasm. Cancer, v. 85, n. I I, p. 2475-84, 1999.

15. IVANOVA, R. et al. Diffuse (or multinodular) follicular variant of papillary thyroid carcinoma: a clinicopathologic and immunohistochemical analysis of ten cases of an agressive form of differentiated thyroid carcinoma. Virchows Arch, v. 440, p. 4I 8-24, 2002.

16. KRAGSTERMAN, B. et al. Cytokeratin 19 expression in papillary thyroid carcinoma. Appl Immunohistochem. Molec Morphol, v. 7, p. $181-5,1999$

17. LOGMANS, S. C. et al. Expression of cytokeratins and vimentin in epithelial cells of normal and pathologic thyroid tissue. Virchows Arch, v. 4I 0, p. 347-54, 1987.

18. MAI, K. T. et al. Papillary thyroid carcinoma and related thyroid neoplastic lesions: a light microscopic study with emphasis on nuclear changes. Tumor, v. 86, p. 238-49, 2000.

19. MAI, K.T. et al. Follicular adenoma with papillary architecture: a lesion mimicking papillary thyroid carcinoma. Histopathology, v. 39, p. 25-32, 2001 
20. MIETTINEN, M. et al. Keratin subsets in papillary and follicular thyroid lesions. Virchows Arch, v 431, p. 407- 13, 1997.

21. NASCIMENTO, M. C. et al. Differential reactivity for galetin-3 in Hurthle cell adenomas and carcinomas. Endocr Pathol, v. 12, n. 3, p. 275-9, 200।.

22. ORLANDI, F. et al. Galectin-3 is a presurgical marker of human thyroid carcinoma. Cancer Res, v. 58, p. 30 15-20, 1998.

23. RAPHAEL, S. J. et al. High-molecular-weight cytokeratin and cytokeratin-19 in the diagnosis of thyroid tumors. Mod Pathol, v 7, p. 295-300, 1994.

24. ROSAI, J. et al. Tumor of the thyroid gland. In: Atlas of Tumor Pathology. Third serie, fascicle 5. Washington, D.C.: Armed Forces Institute of Pathlogy, 1992.

25. SAGGIORATO, E. et al. Galectin-3 as a presurgical immunocytodiagnostic marker of minimally invasive follicular thyroid carcinoma. J Clin Endocr Metab, v. 86, p. 5152-8, 2001.

26. SAHOO, S. et al. Cytokeratin 19 immunoreactivity in the diagnosis of papillary thyroid carcinoma. Am J Clin Pathol, v. I 16, p. 696-702, 2001.

27. SCHELFHOUT, L. J. D. M. et al. Expression of keratin 19 distinguishes papillary thyroid carcinoma from follicular carcinoma and follicular thyroid adenoma. Am J Clin Pathol, v. 92, n. 5, p. 654-8, 1989.

28. WILSON, N.W. et al. Epithelial markers in thyroid carcinoma: an immunoperoxidase study. Histopathology, v. 10, p. 81529, 1986.

29. XU, X. C. et al. R. Differential expression of galectin-I and galectin-3 in thyroid tumors. Am J Path, v. 147, p. 815-22, 1995. 